\title{
Avaliação do uso e ocupação do solo no município de Pilõezinhos-PB, de 1984-2016 utilizando o geoprocessamento
}

\author{
Evaluation of land use in the municipality of Pilõezinhos (PB) between 1984 and 2016
}

\author{
SILVA $^{1}$, P. L. F.; SILVA, A. J. ${ }^{2}$ \\ pedroluanferreira@gmail.com
}

\begin{abstract}
Resumo
O avanço e popularização dos SIG (Sistemas de Informações Geográficas) tem viabilizado a execução de diversos tipos de mapeamentos, dentre eles, o uso das terras, onde, também, é possível analisar as mudanças ocorridas ao longo dos anos. No caso específico do município de Pilõezinhos (PB), observa-se que o mesmo sofreu modificações em sua estrutura fundiária e ambiental com o passar dos anos, o que motivou a realização deste estudo. Desse modo, objetivou-se aqui, avaliar as mudanças do uso das terras no município de Pilõezinhos, entre os anos de 1984 e 2016. As imagens foram coletadas no catálogo de imagens do INPE (Instituto Nacional de Pesquisas Espaciais)- INPE, compreendendo os anos de 1984, 1995, 2004 e 2016. Os referidos mapas foram gerados, levando em consideração as áreas maiores que seis hectares, seguindo a norma proposta pelo IBGE (2010). A partir de então, observouse que o município de Pilõezinhos apresenta redução de sua área florestal devido à ocupação urbana e agrícola. A savanização do solo do município é consequência da fragilidade edáfica dos solos agricultáveis.
\end{abstract}

Palavras-chave: uso da terra, degradação ambiental, município de Pilõezinhos (PB).

\begin{abstract}
The advance and popularization of the GIS (Geographic Information System) has made possible the execution of several kind of mappings, among them, the use of the land, where, its possible to analyze the changes that happened during all over years. In the specific case, of the municipality of Pilõezinhos (PB), it is observed that it has suffered modifications in your land and enviromental structure over the years, and it motivated this research. This way, the objective of this is to evaluate the changes of the use of the land in Pilõezinhos, between 1984 and 2016. The images were collected in the catalog of images of the INPE (National Institute of Space Research), comprising the years of 1984, 1995, 2004 and 2016. The maps used were generated, taking into account areas larger than six hectars, following rules of the IBGE (2010). Thereafter, it was observed that Pilõezinhos presents a reduction of its forest area due to urban and agricultural occupation. The savanization of the soil of the municipality is a consequence of the arable soils.
\end{abstract}

Keywords: use of the land, enviromental degradation, municipality of Pilõezinhos

(PB)

\section{INTRODUÇÃO}

O solo é um sistema aberto não renovável que está sobre constante transformação, seja ela de ordem antropogênica ou de ordem natural. Essas características o torna altamente suscetível a impactos ambientais, tais como: erosão, poluição, perda de cobertura vegetal e incapacidade de resiliência. O tipo de manejo ao qual o solo é submetido é determinante para a sustentabilidade e aproveitamento de seu potencial (DIEL et al., 2013).

O Potencial do solo é determinado pelo sistema de capacidade de uso das terras, que consiste nas combinações do efeito do clima, características físicas e químicas do solo e os aspectos 
do relevo, como forma de classificar e limitar o solo quanto seu uso para atividades agrícolas ou sua predisposição a riscos de degradação (GARCIA et al., 2005).

A delimitação do solo dentro de sua capacidade de suporte é fundamental para o planejamento socioeconômico das atividades agrícolas, industriais e ambientais. A grande demanda por alimentos e a urbanização desenfreada, desencadearam mudanças significativas nos sistemas de produção rural, sobrepondo o monocultivo e explorando, ao máximo possível, a capacidade de suporte do solo.

Alguns atributos como declividade, profundidade do solo, drenagem, textura e estrutura, além da aptidão à mecanização, com tração mecânica e animal (FRANCISCO et al., 2013), são desconsiderados no processo de ocupação do solo; implicando em seu empobrecimento e na baixa produtividade das culturas, que resulta na diminuição do nível socioeconômico e tecnológico da população rural (RAMPIM et al., 2012).

O sensoriamento remoto e o geoprocessamento, são meios que nos permite o uso de imagens de satélite, bases computacionais e softwares, para o processamento de dados contidos em uma base de dados georreferenciada, usando recursos analíticos, gráficos e lógicos, para a obtenção e apresentação das transformações desejadas (XAVIER, 1992; OLIVEIRA, 2013).

A utilização dos SIG para a geração de mapas de uso das terras é uma ferramenta de grande importância, pois, além da obtenção de parâmetros qualitativos e quantitativos (GONÇALVES; ARAÚJO, 2013), ele torna possível a elaboração de mapas através da integração de dados espaciais, permitindo propor alternativas para diminuir impactos identificados no meio ambiente (SENA et al., 2012), como também das áreas mais propicias para o desenvolvimento da agricultura, pecuária e atividades industriais.

O município de Pilõezinhos está localizado na microrregião geográfica de Guarabira e na mesorregião do Agreste paraibano. É um município com tradição agrícola e sua economia gira em torno da agricultura familiar. O sistema de produção rural que existe nos dias atuais segue os mesmos moldes dos sistemas tradicionais de produção de algumas décadas atrás, onde se realizava a supressão da cobertura vegetal para a produção de alimentos, com baixo emprego tecnológico e em contraposição aos moldes de conservação ambiental.

A dependência da fertilidade natural do solo e a ocupação de áreas inapropriadas sem aptidão para a produção agrícola, modificaram o ambiente rural do município de Pilõezinhos, ocasionando elevado êxodo rural e um baixo nível econômico da população.

Diante da carência de informações na literatura e das mudanças ocorridas no âmbito do processo de uso e ocupação do solo no município, objetivou-se com esse trabalho, avaliar o uso do 
solo no município de Pilõezinhos entre os anos de 1984 e 2016, utilizando SIG como subsídio à tomada de decisões no processo de reorganização do espaço rural do município.

\section{METODOLOGIA}

O município de Pilõezinhos está situado entre as coordenadas geográficas $6^{\circ} 48^{\prime} 45^{\prime}$,

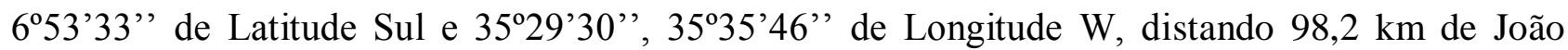
Pessoa, capital do estado da Paraíba (SILVA, 2016a).

O município possui uma área territorial de aproximadamente $44 \mathrm{~km}^{2}$, localizando-se na microrregião de Guarabira e na mesorregião geográfica do Agreste paraibano (Figura 1) (IBGE, 2014). O clima do município é do tipo (As') - quente e úmido, com chuvas de outono-inverno e temperatura média anual variando entre $20^{\circ}$ e $36^{\circ}$ (FRANCISCO et al., 2015). A precipitação pluviométrica gira em torno de $1200 \mathrm{~mm}$ anuais. Os solos que predominam no município são o Argissolo Vermelho amarelo eutrófico e o Latossolo Vermelho amarelo distrófico típico (EMBRAPA, 2013).
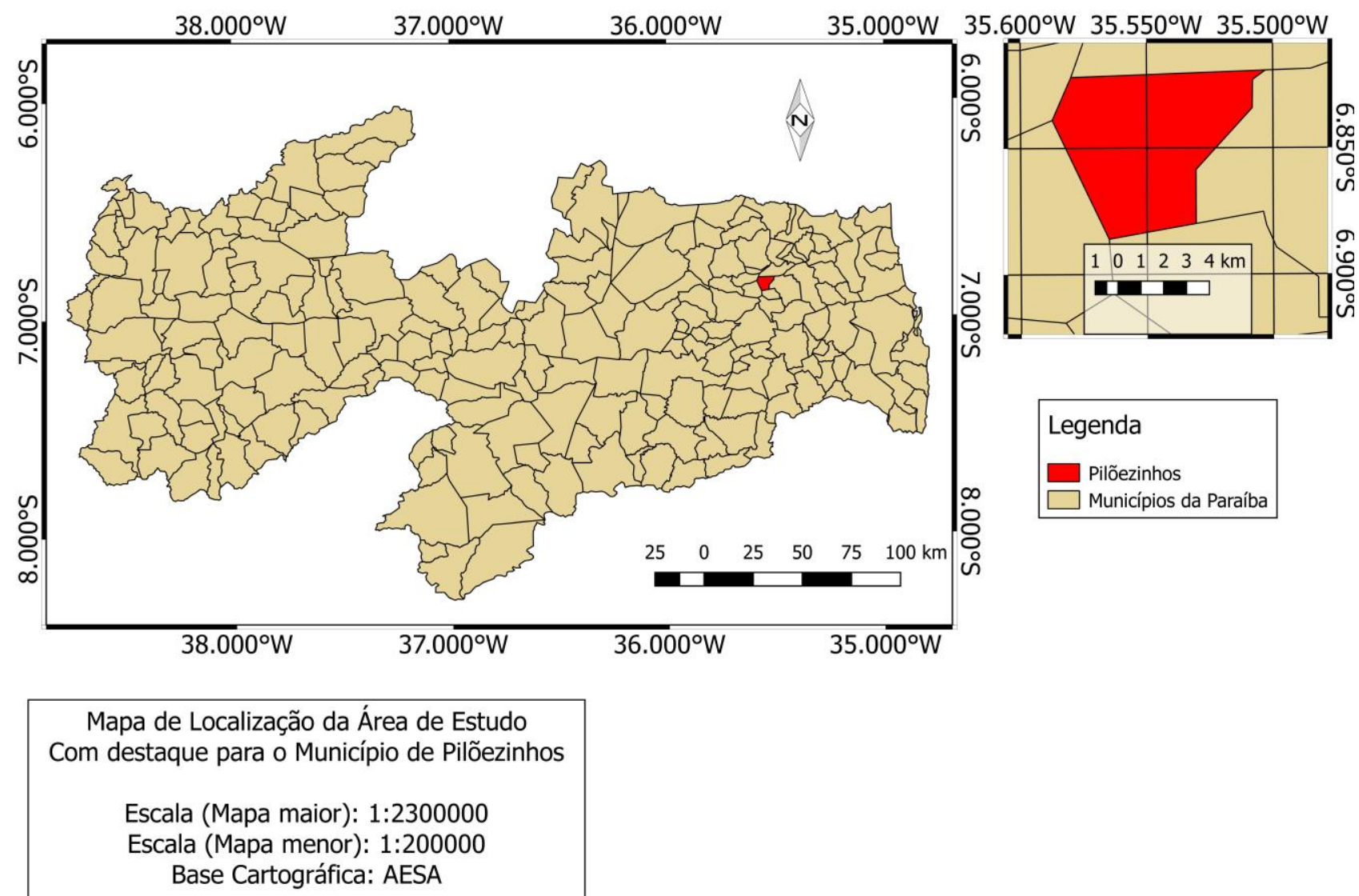

Figura 01. Mapa de localização do município de Pilõezinhos-PB. Fonte: Os autores.

Segundo IBGE (2017a), o município está inserido no bioma Caatinga, e, conforme apresentado em BRASIL (2006) e IBGE (2004), em Pilõezinhos, ocorrem 3 tipos de vegetação, 
Floresta Ombrófila Aberta Submontana, Savana-Estépica e a transição entre Savana-Estépica e Floresta Estacional, além das Atividades Agrárias. A área estudada encontra-se na área de transição entre as vegetações de Agreste e a de Brejo de Altitude da Paraíba. Segundo Tabarelli e Santos (2004), Brejos de altitude são áreas onde a altitude causa chuvas orográficas, criando "ilhas" de vegetação úmida, geralmente, de mata atlântica, em meio à Caatinga seca. Essa condição é confirmada em Pilõezinhos pela ocorrência de Floresta Ombrófila e Estacional em proximidade a Savana-Estépica, característica da Caatinga. A classificação de vegetação usada, nesse trabalho, baseia-se no Manual Técnico da Vegetação Brasileira (IBGE, 2012).

As florestas caracterizam-se pelo adensamento de árvores altas, com redução da qualidade de luz que chega ao solo, o que limita o desenvolvimento das sinúsias herbáceas e arbustivas. (IBGE, 2012). O porte florestal também é caracterizado por plantas com altura entre 20 e 50 metros.

O porte savânico se caracteriza por vegetação mais baixa, com predominância do porte arbustivo e herbáceo, as árvores geralmente tem altura entre 3 e 10 metros. A Savana-Estépica é um tipo de vegetação com porte savânico adaptada às condições de aridez do semiárido brasileiro. Neste trabalho, usa-se o termo "Savana" para designar tanto a vegetação nativa em equilíbrio, quanto para áreas de floresta em estágio primário de regeneração.

As imagens utilizadas nesse estudo foram escolhidas a partir da disponibilidade do catálogo de imagens do Instituto Nacional de Pesquisas Espaciais. As imagens utilizadas foram capturadas em períodos semelhantes dos anos, como forma de reduzir os efeitos do clima sobre a vegetação. As especificações das imagens estão listadas na Tabela 1.

Tabela 1: Especificações das imagens de satélite utilizadas. Fonte: INPE (2017).

\begin{tabular}{ccccccc}
\hline Ano & Satélite & Sensor & Órbita & Ponto & Data & Resolução \\
\hline 1984 & Landsat 5 & TM & 214 & 65 & $10 / 06 / 1984$ & $30 \mathrm{~m}$ \\
1995 & Landsat 5 & TM & 214 & 65 & $11 / 07 / 1995$ & $30 \mathrm{~m}$ \\
2004 & Landsat 5 & TM & 214 & 65 & $19 / 07 / 2004$ & $30 \mathrm{~m}$ \\
2016 & ResourceSat-2 & AWIF & 339 & 084 & $27 / 07 / 2016$ & $55 \mathrm{~m}$ \\
\hline
\end{tabular}

A composição colorida atribuída obedeceu à metodologia proposta pelo IBGE (2012, p.236), onde foram utilizadas as bandas 5 (vermelho), 4 (verde) e 3 (azul). Foram incluídas na classificação as áreas com extensão territorial maior que 6 hectares (250m x 250m), áreas de extensão territorial menor foram incluídas como intercalações das classes de uso das terras.

Após a realização da composição colorida utilizando o software livre Quantum GIS® versão 2.18.9, as imagens foram classificadas segundo os usos encontrados, totalizando seis: Floresta, Savana, Atividades Agrárias, Intercalação de Savana com Atividades Agrárias, Intercalação de 
Florestas com Atividades Agrárias e Zona Urbana. Os critérios utilizados para classificação visual das classes de uso foram as cores e seus graus de intensidade, verde, vermelho e branco (Figura 2).

Posteriormente, gerou-se um mosaico das imagens, no intuito de cobrir toda a área analisada.

Por fim, para a delimitação dos tipos de uso, criou-se um Shapefile, baseado na malha digital de municípios disponível em IBGE (2017c), onde, a partir deste arquivo vetorial, foram delimitadas as feições, onde, posteriormente, foram calculadas as áreas dos tipos de uso.

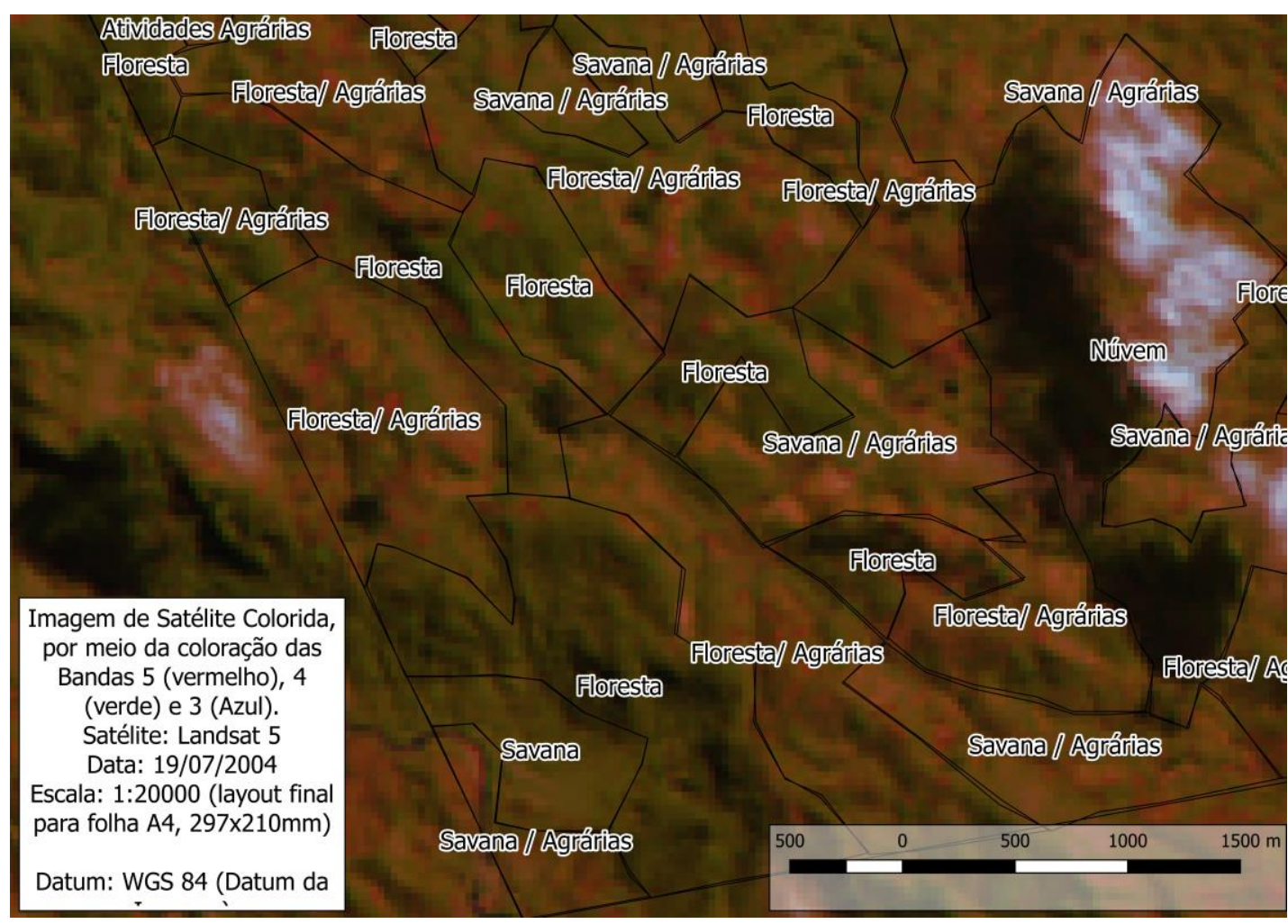

Figura 02. Exemplo de imagem de satélite após a aplicação da composição colorida. Fonte: Os autores.

$\mathrm{Na}$ imagem, de acordo com os canais atribuídos a cada uma das bandas no processo de composição colorida, a cor verde indica a ocorrência de vegetação de maior porte (Floresta e Savana), sendo os tons mais escuros referentes à ocorrência de vegetação florestal e, os tons mais claros, referentes à vegetação de porte savânico. As áreas com Atividades Agrárias foram indicadas pelas colorações verde, vermelha e branco, com predominância da cor vermelha. A zona urbana apresenta cores vermelha e branca, com predominância da branca.

As cores apresentadas nos mapas finais foram adaptadas das metodologias utilizadas por IBGE (2004) e Brasil (2006). O presente trabalho e os dois citados acima utilizaram as cores indicadas por metodologia proposta pelo IBGE (2012). 


\section{RESULTADOS E DISCUSSÃO}

Os dados referentes ao ano de 1984 apresentados na Figura 3 e na Tabela 2, mostram que 47\% da área territorial do município em análise se apresentava ocupada por áreas de savana e 19\% por atividades agrárias. Essa condição indica a existência de agricultura em pequenas áreas, com predomínio da agricultura familiar.

Tabela 02. Percentual de ocupação do solo do município de Pilõezinhos-PB, 1984-2016. Fonte: Os autores (2016).

\begin{tabular}{lcccccc}
\hline \multicolumn{7}{c}{ Ocupação } \\
\hline Ano & Ativ. Agrária & Florestas & Floresta/ agr. & Savana & Savan./ Agr. & Área urbana \\
\hline 1984 & $19,7 \%$ & $19,1 \%$ & $0,8 \%$ & $17,9 \%$ & $42,5 \%$ & $0 \%$ \\
1995 & $16,6 \%$ & $23,2 \%$ & $34,7 \%$ & $2,5 \%$ & $22,0 \%$ & $0,5 \%$ \\
2004 & $2,7 \%$ & $22,0 \%$ & $40,8 \%$ & $3,0 \%$ & $15,5 \%$ & $1 \%$ \\
2016 & $26,2 \%$ & $14,3 \%$ & $8,1 \%$ & $3,9 \%$ & $43,9 \%$ & $3,6 \%$ \\
\hline
\end{tabular}

O censo agrícola de 1975 (IBGE, 1979), salienta que em Pilõezinhos, existia 409 estabelecimentos agrícolas distribuídos em 3.225 hectares, a maioria com tamanhos variando entre 1 e 10 hectares. O censo de 1980 (IBGE, 1984) também indica condição semelhante, com 4.424 hectares distribuídos entre 574 estabelecimentos, a maioria entre 1 e 10 hectares.

Observa-se que, no ano de 1984, apenas 641,45 hectares de área no município de Pilõezinhos estava ocupado por remanescentes de floresta (Tabela 4). Uma explicação para essa redução das matas na região Nordeste está relacionada às atividades agropecuárias com predomínio da criação de gado, da exploração de madeira e, das práticas de agricultura, principalmente, pela ocupação por cana-de-açúcar (TABARELLI et al., 2005). 


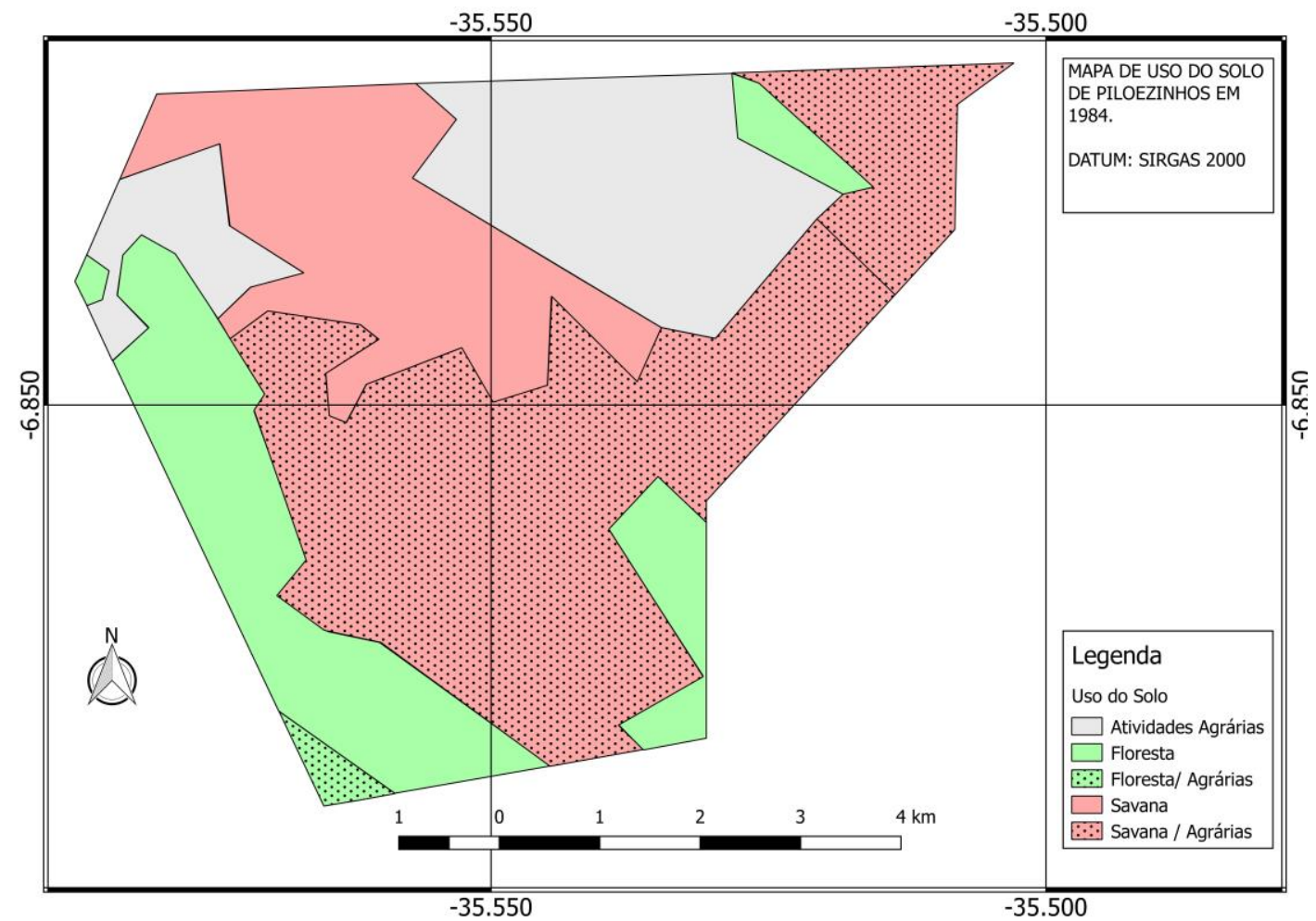

Figura 03. Uso do solo no município de Pilõezinhos-PB em 1984. Fonte: Os autores.

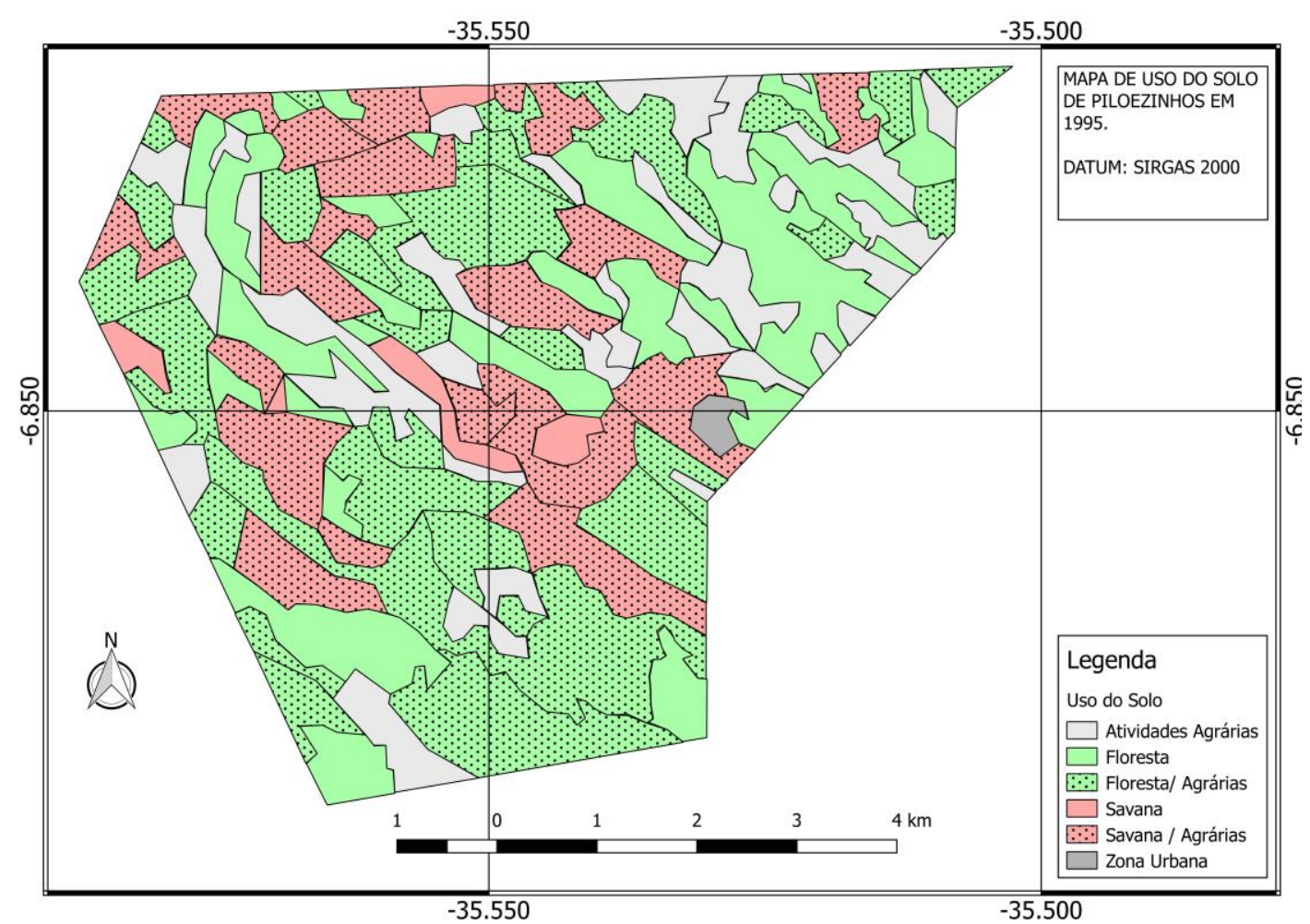

Figura 04. Mapa de uso do solo do município de Pilõezinhos, 1995. Fonte: Os autores.

A Partir de 1995 (Figura 4 e Tabela 2), observou-se a ocorrência de um leve aumento das áreas ocupadas com florestas e um expressivo aumento das áreas ocupadas com atividades agrárias, em detrimento das áreas de savana e savana com atividades agrárias. A grande seca de 1993 
vivenciada pelo Nordeste brasileiro deve ter culminado na diminuição da área ocupada por atividades agrárias no município de Pilõezinhos, como observado por Silva et al. (2014).

Já o aumento das áreas de florestas em função da redução das atividades agrárias pode ser reflexo do pousio das áreas que foram cultivadas e da regeneração natural do banco de sementes do solo, principalmente de espécies pioneiras, que apresentam rápido crescimento. $\mathrm{O}$ banco de sementes do solo representa uma importante alternativa de restauração dos ecossistemas (CORREIA; MARTINS, 2015), mesmo aqueles que apresentam um histórico de uso e ocupação por atividades agrárias e ocupação por pastagens (HOLL, 2013).

A manutenção de áreas de floresta é fundamental para o equilíbrio ambiental, pois além de contribuir com a mitigação dos efeitos das mudanças climáticas, favorece a preservação dos recursos hídricos e diversidade de animais e plantas.

Tabela 03. Evolução do uso das terras em (ha). Fonte: Os autores.

\begin{tabular}{lcccccc}
\hline Ano & Agrária & Floresta & $\begin{array}{c}\text { Floresta/ } \\
\text { agr. }\end{array}$ & Savana & $\begin{array}{c}\text { Savana/ } \\
\text { Agr. }\end{array}$ & Área urbana \\
\hline 1984 & 849,29 & 849,58 & 44,71 & 782,50 & 1878,00 & 0,00 \\
1995 & 760,15 & $1.028,58$ & $1.542,66$ & 134,14 & 970,60 & 22,15 \\
2004 & 178,85 & 961,36 & $1.833,30$ & 134,14 & 683,10 & 24,40 \\
2016 & $1.171,52$ & 639,42 & 362,18 & 174,38 & 1963,16 & 160,97 \\
\hline
\end{tabular}

Em 2004, apenas 2,7\% do município tinha desenvolvimento de agropecuária em áreas maiores que 6 ha, 56\% era vegetação intercalada com atividades agrárias, principalmente floresta. Reforçando as condições já apresentadas em 1984 e 1995. Brasil (2008), apresenta que as alterações climáticas que já ocorreram e que vão continuar ocorrendo, dão mais incerteza aos produtores, ocasionando a redução na área plantada.

Segundo o Censo Agropecuário de 2016, IBGE (2017b), o município de Pilõezinhos conta com 676 estabelecimentos agrícolas ocupando 3752 ha. A partir desses dados pode-se afirmar que o referido município tem parte importante de suas atividades agrícolas realizadas por pequenos agricultores em pequenas propriedades, logo, as áreas de vegetação também irão ocorrer em pequenas áreas dentro dessas propriedades.

O mosaico de coloração em tons verdes encontrado na Figura 5, está relacionado à transição entre floresta e atividades agrárias. O acelerado processo de antropização das áreas de floresta que apresentam condições edáficas favoráveis ao desenvolvimento das práticas agropecuárias contribuiu com o processo de degradação desse ambiente. A busca por solos férteis nos remanescentes de Mata Atlântica é resultante do esgotamento dos solos nas áreas de cultivo, em função da ausência de técnicas de manejo e conservação do solo e da água. 


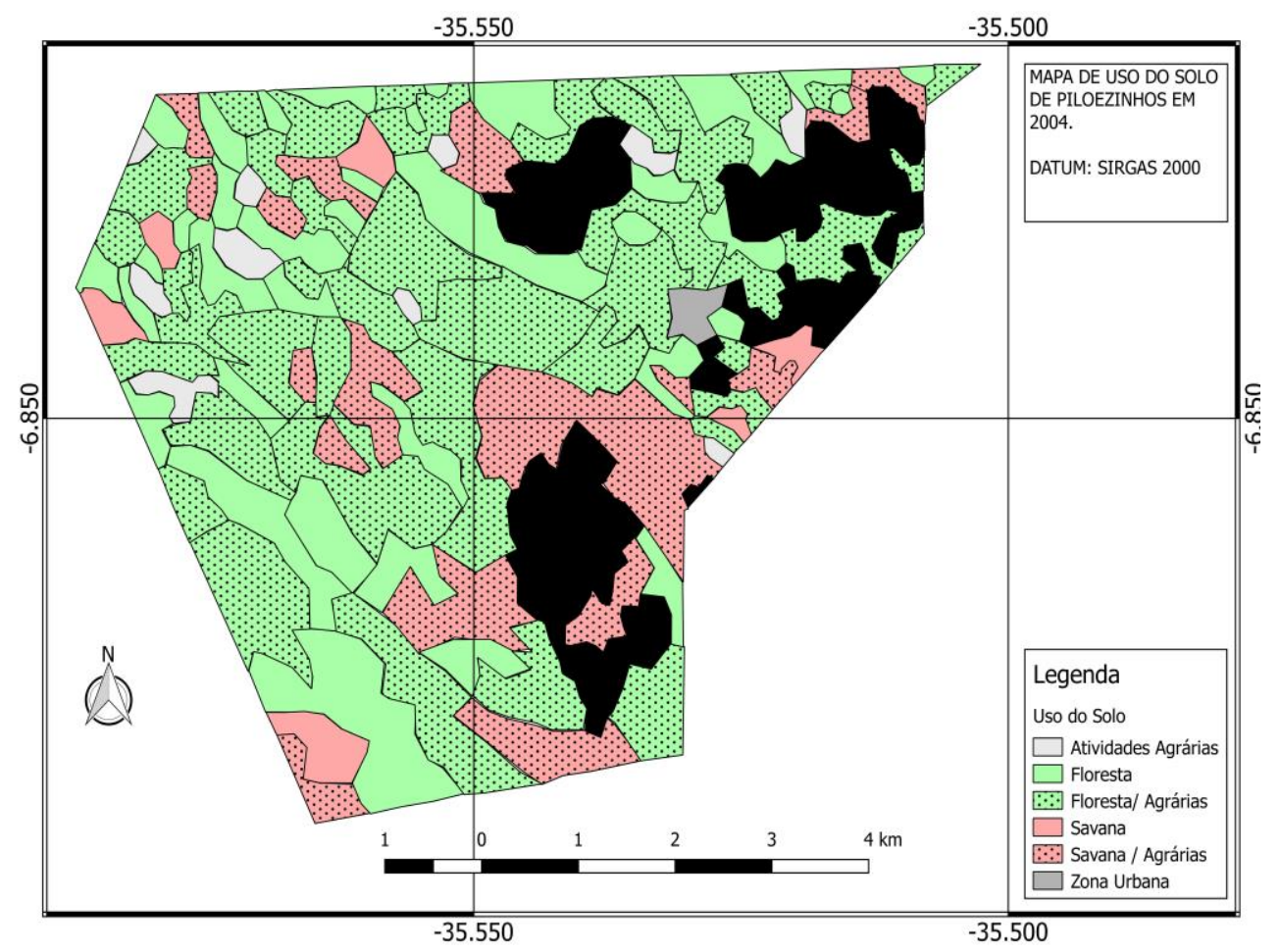

Figura 05. Mapa de uso do solo do município de Pilõezinhos, 2004. Fonte: Os autores.

A exaustão edáfica do solo favorece ao aparecimento de erosão e degradação das áreas de cultivo, devido à diminuição da cobertura vegetal, por causa da escassez de nutrientes no solo, fundamentais para o crescimento dos vegetais e desempenho da produtividade das culturas. A supressão da cobertura vegetal é uma das principais causas de agravamento dos efeitos degradacionais do solo (SILVA; CRUZ, 2016).

Durante o processamento das imagens verificou-se que, as maiores áreas florestais, sem atividades agrárias, acorrem em locais de forte declive, onde há dificuldade para produção agrícola ou pecuária. Fora desses pontos de difícil acesso, não ocorrem significativos remanescentes florestais. 


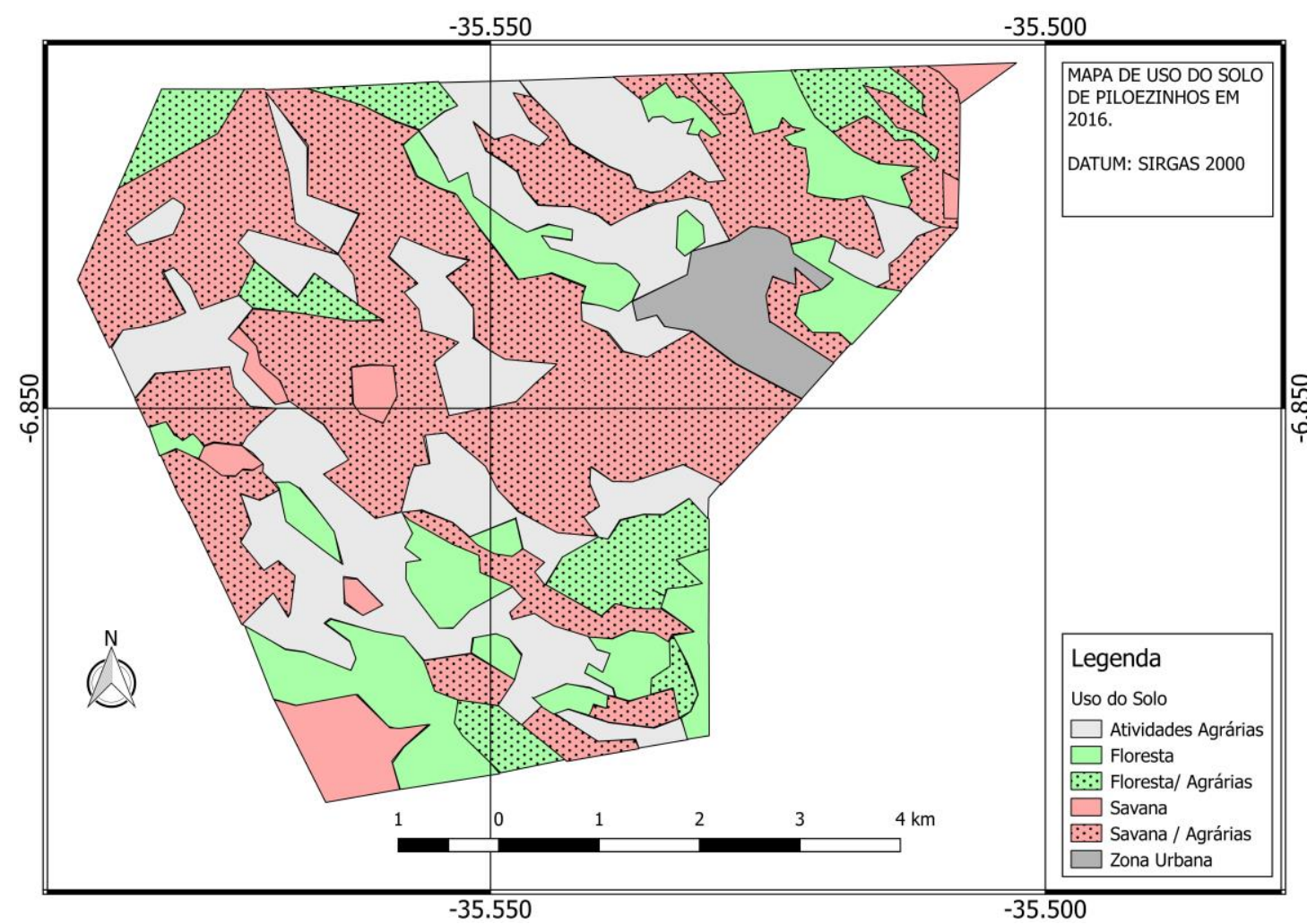

Figura 06. Mapa de uso do solo do município de Pilõezinhos, 2016. Fonte: Os autores.

Observa-se um aumento no processo de savanização das áreas de floresta no município de Pilõezinhos. A fragilidade dos solos através das atividades agropecuárias favorece à invasão e colonização de espécies exóticas adaptadas a ambientes mais inóspitos, comprometendo a regeneração das espécies nativas. Segundo Leão et al. (2011), as principais causas diretas de perda de biodiversidade através das conversões dos hábitats estão relacionadas às atividades humanas, como o avanço da fronteira agrícola, as mudanças climáticas e ao processo de uso e ocupação do solo.

Silva et al. (2016b), verificaram que uma das principais causas de degradação das áreas agrícolas do município de Pilõezinhos foi a migração e o abandono das áreas de cultivo em um período de tempo muito curto, no máximo três safras em anos consecutivos. A extração de nutrientes pelos vegetais sem a devida reposição, favorece o processo de degradação do solo, tanto pelo processo de acidificação, devido à remoção de bases, como, também, pela perda de ciclagens de nutrientes da matéria orgânica.

Segundo Pedron et al. (2016), a expansão urbana acelerada tem provocado diversos impactos negativos ao meio ambiente, excedendo a capacidade de suporte dos solos das cidades. Entre esses impactos pode-se destacar a poluição das fontes de água, deposição de resíduos em locais inadequados além da falta de acesso as redes de esgoto e água tratada. Araújo e Filho (2010), 
verificaram que a acelerada expansão da urbanização é uma das principais causas de contaminação de água por metais pesados.

A evolução da área ocupada pela zona urbana foi crescente entre os anos de 1995 e 2016 (Tabela 2 e 3), partindo de 22,35 hectares para 160,97. A concentração das atividades industriais, financeiras, hospitalares e educacionais em área urbana favoreceu o processo de crescimento das cidades, principalmente após os anos 2000. O elevado êxodo rural e as instabilidades das condições socioeconômicas das comunidades rurais do município de Pilõezinhos favoreceram o processo de ocupação do solo da zona urbana, com consequências aparentes para os meios ambiente e social.

Observa-se na Figura 5, um aumento das atividades agrárias e redução das áreas de floresta no município de Pilõezinhos. As condições climáticas favoráveis e a grande demanda de alimentos no Brasil, favoreceu o desenvolvimento agrícola das pequenas propriedades, principalmente as de cunho familiar.

Conforme verificado através do processamento das imagens de satélite que foram coletadas para este estudo, o município de Pilõezinhos possui uma área territorial de 4.471,48 hectares (Tabela 4), sendo que 1.172,97 são ocupados por atividades agrárias, 641,48 ocupados por área de florestas, 363,56 por intercalação entre áreas florestais e atividades agrárias, 173, 05 por áreas de savana, 1.963, 16 por intercalação entre atividades agrárias e savanas e, 161,25 hectares ocupados por urbanização.

Tabela 04. Ocupação do solo em Pilõezinhos em hectares, em 2016. Fonte: Os autores.

\begin{tabular}{cc}
\hline Ocupação & Área em hectares \\
\hline Atividades Agrárias & $1.172,97$ \\
Floresta & 641,45 \\
Floresta/ agrárias & 363,56 \\
Savana & 173,05 \\
Savana/ Agrárias & $1.963,16$ \\
Urbanização & 161,25 \\
\hline Total & $\mathbf{4 . 4 7 1 , 4 8}$ \\
\hline
\end{tabular}

Entre 1984 e 2016 observou-se uma redução da área ocupada por florestas, decrescendo de 849,58 hectares para 639,42 hectares atuais. Segundo a organização não governamental SOS Mata Atlântica (2016), apenas 10,30 km² do território do município em análise são ocupados por remanescente de Mata Atlântica. Fruto do esforço de órgãos governamentais na tentativa de manter preservada a biodiversidade das florestas remanescentes no Piemonte da serra da Borborema, onde está localizado o município. 
Entre as atividades caracterizadas, observa-se que a savana e atividades agrárias se sobressaem com a maior área de ocupação. A área de ocupação urbana apresenta 160, 97 hectares, a menos representativa do total em uso.

A localização do município analisado em uma região conhecida por ter grande aptidão para a produção de alimentos e ser grande fonte de recursos hídricos torna-o promissor para a produção de gêneros agropecuários, levando em consideração as boas práticas de manejo e conservação do solo.

O relevo acidentado do referido município favorece à erosão por eventos climatológicos diversos, principalmente pela pluviometria, pois o mesmo está localizado em uma região que apresenta uma média pluviometria de aproximadamente $1.200 \mathrm{~mm}$ anuais.

Observa-se que as áreas de florestas como as áreas de interação entre floresta e agricultura apresentaram as maiores taxas de redução ao longo do tempo, fato esse devido à expansão das atividades agropecuárias e da ocupação urbana. Em 2016, as áreas ocupadas por atividades agrárias apresentavam 1.171,52 hectares, um aumento de 992,57 hectares em relação ao ano de 2004.

O crescente desmatamento para à ocupação por agricultura e pecuária representa uma das principais causas de impactos ambientais, não respeitando à legislação ambiental vigente, nem as condições ambientais que podem servir de suporte para a realização dessas atividades.

O solo quando é cultivado fora da sua capacidade de suporte perde a eficiência de seus atributos, que são altamente modificados através das práticas agrícolas. A matéria orgânica presente em superfície perde sua capacidade de resiliência devido ao processo de erosão, por meio de ravinas e voçorocas. A combinação de fatores ambientais tais como tipos de solo, formas de relevo e cobertura vegetal, juntamente com o uso da terra rural e urbano, elevam o risco de erosão dos solos (MARÇAL; GUERRA, 2001), necessitando à adoção de técnicas que favoreçam o processo de remediação da degradação e conservação dos solos.

Algumas práticas edáficas, mecânicas e vegetativas são de grande importância no processo de planejamento de uso das terras, pois, quando utilizadas de forma adequada, favorece à preservação do meio, além de contribuir no processo de ganhos econômicos. As lavouras do município de Pilõezinhos se localizam em áreas com grau de declividade acentuado, favorecendo os processos de degradação. A adoção de técnicas como o terraceamento e plantio em curvas de nível são fundamentais para a conservação do solo em áreas de lavoura, pois disciplina o escoamento das águas da chuva, diminuindo o arraste de sedimentos "morro abaixo" (MACHADO; WADT, 2016).

Desse modo, no contexto do município em análise, observou-se uma redução da área ocupada por atividades agrárias entre a década de oitenta e o ano de dois mil e quatro, partindo de 849,29 hectares ocupados em 1984 para 178,85 hectares em 2004, uma redução de 670,44 hectares 
de área ocupada pelo cultivo agrícola, em 2016 há um aumento para 1.171,52 hectares. Esse aumento pode ocorrer devido as condições de resolução do Satélite ResourceSat-2 ser menor que a do Landsat-5, modificando os tons de coloração das imagens durante as coletas para realização do estudo.

\section{CONSIDERAÇÕES FINAIS}

O município de Pilõezinhos apresenta redução da área de florestas, devido ao crescente processo de uso das terras por atividades agrárias e desmatamento. A savanização das áreas de florestas nativas é resultante da adoção de práticas agrícolas inadequadas e da fragilidade edáfica dos solos.

A utilização dos Sistemas de Informações Geográficas para a geração dos mapas de uso das terras, favoreceu à caracterização e ao dimensionamento das práticas de ocupação do solo no município em questão. Foi possível observar as mudanças que ocorreram na paisagem da área analisada ao longo do tempo, com destaque para a savanização e a área com ocupação por atividades agrárias que no ano de 2016 somaram 68,97\% das áreas de solo ocupada no município, ou seja, de 4.471,48 ha, 3.076,48 estão ocupados por savana e atividades agrárias.

\section{REFERÊNCIAS}

ARAÚJO, J.B.S.; PINTO FILHO, J.L.O. Identificação de fontes poluidoras de metais pesados nos solos da bacia hidrográfica do rio Apodi-Mossoró/RN, na área urbana de Mossoró-RN. Revista Verde de Agroecologia e Desenvolvimento Sustentável, Pombal, v.5, n.2, p. 80-94. 2010.

BRASIL. Aquecimento Global e a Nova Geografia da Produção Agrícola no Brasil. Brasilia: Embrapa, 2008. 84 p.

BRASIL. Guarabira: cobertura vegetal dos biomas brasileiros (ano base 2002). FOLHA SB25-Y-A MIR-208. 2006. Escala: 1:250.000.

CORREIA, G. G. S.; MARTINS, S. V. Banco de sementes do solo de floresta restaurada, reserve natural Vale, ES. Floresta e Ambiente, Seropédica, 22(1): 79-87, 2015. http://dx.doi.org/10.1590/2179-8087.096714.

DIEL, P.S.; COSTA, P.F.; OLIVEIRA, P.S.R.; SILVA, N.L.S.; ROSSET, J.S. Capacidade de uso de solo das propriedades rurais da microbacia do córrego Guará no Município de Marechal Cândido Rondon/PR. Scientia Agraria Paranaensis, Marechal Cândido Rondon, v. 12, sup., p. 400-410. 2013.

EMPRESA BRASILEIRA DE PESQUISA AGROPECUÁRIA (EMBRAPA). Sistema brasileiro de classificação de solos. 3. ed. Brasília: Embrapa, 2013. 353p. 
FRANCISCO, P.R.M.; CHAVES, I.B.; LIMA, E.R.V. Classificação de terras para mecanização agrícola e sua aplicação para o estado da Paraíba. Revista Educação Agrícola Superior, Brasília, v.28, n.1, p. 30-35. 2013.

FRANCISCO, P.R.M.; MEDEIROS, R.M.; SANTOS, D.; MATOS, R.M. Classificação climática de Köppen e Thornthwaite para o estado da Paraíba. Revista Brasileira de Geografia Física, Recife, v. 08, n. 04, p. 1006-1016, 2015.

GARCIA, G.J.; ANTONELLO, S.L.; MAGALHÃES, M.G.M. Nova versão do sistema de avaliação de terras-SIAT. Engenharia Agrícola, Jaboticabal, v.25, n.2, p.516-529. 2005.

GONÇALVES, S.R.A.; ARAÚJO, R.R. Elaboração de mapas temáticos por meio do Sistema de Informação Geográfica (SIG) para caracterização das áreas de contribuição da bacia do manancial Rio Santo Anastácio. Tópos, Presidente Prudente, v. 7, n. 1, p. 58-67, 2013.

HOLL, K. D. Restoring Tropical Forest. Nature Education Knowledge, 4(4): 4, 2013.

IBGE. INSTITUTO BRASILEIRO DE GEOGRAFIA E ESTATÍSTICA. Paraíba >> Pilõezinhos > censo agropecuário - $\quad 2006 . \quad$ Disponível $\quad$ em: http://cidades.ibge.gov.br/xtras/temas.php?lang=\&codmun=251170\&idtema=3\&search=paraiba|pil oezinhos|censo-agropecuario-2006>. Acesso em: 19 fev. 2017 (b).

IBGE. INSTITUTO BRASILEIRO DE GEOGRAFIA E ESTATÍSTICA Cenco Agropecuário: Paraíba. Instituto Brasileiro de geografia e Estatística, Rio de Janeiro, 1984.

IBGE. INSTITUTO BRASILEIRO DE GEOGRAFIA E ESTATÍSTICA. Censo Agropecuário: Paraíba. Instituto Brasileiro de Geografia e Estatística, Rio de Janeiro, 1979.

IBGE. INSTITUTO BRASILEIRO DE GEOGRAFIA E ESTATÍSTICA. Bases e referenciais: bases cartográficas > malhas digitais. Disponível em: <http://mapas.ibge.gov.br/bases-ereferenciais/bases-cartograficas/malhas-digitais.html>. Acesso em: 10 jun. 2017.

INSTITUTO BRASILEIRO DE GEOGRAFIA E ESTATÍSTICA (IBGE). Manual técnico da vegetação brasileira. Rio de Janeiro: IBGE, 2012. 271 p.

INSTITUTO BRASILEIRO DE GEOGRAFIA E ESTATISTICA (IBGE). Mapa de Vegetação do Brasil. 2004. Escala: 1:5.000.000.

INSTITUTO BRASILEIRO DE GEOGRAFIA E ESTATÍSTICA (IBGE). Paraíba >> Pilõezinhos > infográficos: dados gerais do município. Disponível em: < http://cidades.ibge.gov.br/painel/painel.php?lang=\&codmun=251170\&search=paraiba|piloezinhos|i nfograficos:-dados-gerais-do-municipio>. Acesso em: 18 fev. 2017. (a)

INSTITUTO BRASILEIRO DE GEOGRAFIA E ESTATÍSTICA (IBGE). Produção Agrícola Municipal 2010. Rio de Janeiro: IBGE, 2014. 400 p.

INSTITUTO NACIONAL DE PESQUISA ESPACIAIS (INPE). Divisão de Geração de Imagens (DGI). Disponível em: <http://www.dgi.inpe.br/siteDgi/portugês/index.php>. Acesso em: 19 fev. 2017. 
INSTITUTO NACIONAL DE PESQUISAS ESPACIAIS (INPE). Image Catalog. Disponível em: <http://www.dgi.inpe.br/CDSR/>. Acesso em: 13 dez. 2016.

LEÃO, T.C.C.; ALMEIDA, W.R.; DECHOUM, M.S.; ZILLER, S.R. Espécies invasoras no Nordeste do Brasil: contextualização, manejo e políticas públicas. Recife: CEPAN, 1. ed., 2011. $99 \mathrm{p}$.

MACHADO, P.L.O.A.; WADT, P.G.S. Boas práticas agrícolas: terraceamento. Rio Branco: Embrapa, 1. Ed., 2016. 9p.

MARÇAL, M.S.; GUERRA, A.J.T. Identificação de áreas suscetíveis à erosão dos solos em Açailândia no estado do Maranhão. In: Simpósio Nacional de Controle de Erosão, 7., 2001, Goiânia. Anais... Goiânia: UFG, 2001. p. 1-9.

OLIVEIRA, E.S. Estudo preliminar sobre a evolução do uso e ocupação do solo no município de Planaltina de Goiás. GeoTemas, Pau dos Ferros, v.3, n.1, p. 111-123. 2013.

PEDRON, F.A.; DALMOLIN, R.S.D.; AZEVEDO, A.C.; POELKING, E.L.; MIGUEL, P. Utilização do sistema de avaliação do potencial de uso urbano das terras no diagnóstico ambiental do município de Santa Maria - RS. Ciência Rural, Santa Maria, v.36, n.2, p. 468-477, 2006.

QGIS TRADEMARK. Software QGIS versão 2.18.2. Disponível em: <http://www.qgis.org/pt_BR/site/>. Acesso em: $14 \mathrm{dez} .2016$.

RAMPIM, L.; TAVARES FILHO, J.; BEHLAU, F.; ROMANO, D. Determinação da capacidade de uso do solo usando o manejo sustentável para uma média propriedade em Londrina-PR. Bioscience Journal, Uberlândia, v.28, n.2, p. 251-264. 2012.

SENA, F.T.N.S. SANTIAGO NETO, B.J. LEITE, A.C.S. Uso do geoprocessamento como subsídio à análise ambiental: imagem SRTM na geração de mapas hipsométrico e de declividade das bacias difusas da barragem Boa Esperança no estado do Piauí. In: Simpósio brasileiro de ciências geodésicas e tecnologias da geoinformação, 4, Recife. Anais. Recife: IV SBCGTG, 2012. p. 19-40.

SILVA, F.C.; CRUZ, M.L.B. Análise da fisionomia da cobertura vegetal em ambientes semiáridos: o caso do município de Jaguaretama, estado do Ceará. REGNE- Revista de Geociências do Nordeste, Caicó, v. 2, n. especial, p. 1-9. 2016.

SILVA, J.G.S.; PAULA, L.A.M.; ESMERALDO, G.G.; MONTE, F.C.D. Impactos da seca nas unidades produtivas familiares assentadas. RDE- Revista de Desenvolvimento Econômico, Salvador, v. 16, n. 30, p. 35-45. 2014.

SILVA, P.L.F.; CAVALCANTE, A.C.P.; SILVA, A.G. Análise da produção agrícola proveniente da agricultura familiar do Município de Pilõezinhos-PB. Élisée, Revista de Geografia UEG, Anápolis, v.5, n.1, p.120-133, jan.-jun. 2016 (b).

SILVA, P.L.F.; CAVALCANTE, A.C.P.; SILVA, A.G. Evaluation of degradation of environmental resources: A case study on a rural property Pilõezinhos-PB. Revista Monografias Ambientais, Santa Maria, v.15, n.1, p. 132-140. 2016 (a). 
SOS MATA ATLÂNTICA. Área de Mata Atlântica no município de Pilõezinhos 2015. Disponível em: < http://aquitemmata.org.br/\#/busca/pb/Para\%C3\%ADba/Pil\%C3\%B5ezinhos $>$. Acesso em: 14 dez. 2016.

TABARELli, M.; PINTO, L.P.; SILVA, J.M.C.; HIROTA, M.M.; BEDÊ, L.C. Desafios e oportunidades para a conservação da biodiversidade na Mata Atlântica brasileira. Megadiversidade, Rio de Janeiro, v.1, n.1, p. 132-138. 2005.

TABARELLI, Marcelo; SANTOS, André Mauricio Melo. Uma Breve Descrição Sobre a História Natural dos Brejos Nordestino, In: PÔRTO, Kátia C. et al. Brejos de altitude em Pernambuco e Paraíba: História Natural, Ecologia e Conservação. Brasilia; Ministério de Meio Ambiente, 2004. Cap. 2, p. 17-24.

XAVIER, S.J. Geoprocessamento e análise ambiental. Revista Brasileira de Geografia, v.54, n.3, p. 47-61. 1992.

Recebido em: 14/12/2016

Aceito para publicação em: 08/06/2017 